\title{
Cholecystoduodenal Fistula and Gallstone lleus: A Case Report
}

\author{
Célia Garritano 1,*, Bruna Lago Chaves², Aline Machado Teixeira Auad², Peter França Lins de Carvalho², Thaís de Sousa \\ Gonçalves², and Hiron Marcos Barreto Rodrigues²
}

${ }^{1}$ Department of General and Specialized Surgery, Gaffrée e Guinle Teaching Hospital, Federal University of the State of Rio de Janeiro, Brazil ${ }^{2}$ Resident physician, Gafrée e Guinle Teaching Hospital, Federal University of the State of Rio de Janeiro, Brazil

*Corresponding author: Célia Garritano, Department of General and Specialized Surgery, Gaffrée e Guinle Teaching Hospital, Federal University of the State of Rio de Janeiro, Brazil, Tel: 5521999882814; E-mail: cgarritano@gmail.com

Received: 19 Aug, 2019 | Accepted: 16 Sep, 2019 | Published: 21 Sep, 2019

Citation: Garritano C, Chaves BL, Auad AMT, de Carvalho PFL, de Sousa Gonçalves T, et al. (2019) Cholecystoduodenal Fistula and Gallstone Ileus: A Case Report. J Surg Open Access 5(4): dx.doi.org/10.16966/2470-0991.190

Copyright: (C) 2019 Garritano C, et al. This is an open-access article distributed under the terms of the Creative Commons Attribution License, which permits unrestricted use, distribution, and reproduction in any medium, provided the original author and source are credited.

\begin{abstract}
The gallstone ileus is a serious complication of cholelithiasis due to the formation of a fistula from the gallbladder to the subjacent duodenum. The gallstones are usually large enough to cause intestinal obstruction. The distal ileum, close to the ileocecal valve, is the most common site of obstruction in these cases, where the luminal diameter is narrowed. This condition is currently responsible for $4 \%$ of all the cases of mechanical bowel obstruction. However, when considering a $65+$ age group, the rate goes up to $25 \%$. In conclusion, gallstone ileus is a surgical emergency that, although rare, has high morbimortality rates. We present the case of a patient with an acute abdomen who did not respond to verbal stimuli, with a previous history of gallstone cholecystitis and significant weight loss. The diagnosis was based on anamnesis, physical examination and complementary exams, particularly in imaging exams. Exploratory laparotomy was performed with enterotomy, the removal of the gallstones and enterorrhaphy, without manipulation of the gallbladder or cholecystoduodenal fistula. The postoperative evolution was satisfactory without complications. The patient received hospital discharge in good clinical conditions, with the recommendation to stay in outpatient follow-up.
\end{abstract}

Keywords: Cholecystoduodenal fistula; Gallstone ileus; Acute abdomen; Acute cholecystitis

\section{Introduction}

Lithiasic cholecystitis can have many types of complications, one of them being the formation of bilioenteric fistulas, which can evolve to a bowel obstruction. Gallstone ileus was first described in 1964 by Bartholin [1]. It is a serious and rare complication arising from a previous episode of acute cholecystitis, followed by the inflammation of the tissues that surround the gallbladder, forming adhesions between the gallbladder and the small bowel. The inflammatory tissue binds to all the surrounding tissues, creating multiples adherences onto the gallbladder and the small bowel $[2,3]$. The gallstone gradually erodes the gallbladder and the walls of the bowel, leading to a cholecystoenteric fistula $[4,5]$. The gallstone often migrates to the intestinal lumen and causes a bowel obstruction, a condition which is called gallstone ileus. The most common site of the obstruction is the distal ileum, close to the ileocecal valve, due to its narrower diameter $[1,6]$.

This condition is responsible for between $1 \%$ and $4 \%$ of all cases of mechanic bowel obstruction [2,3,7,8]; however, when considering the $65+$ age group, the rate goes up to $25 \%[2,8]$, and to more than $30 \%$ in individuals over 70 years of age [1]. In estimation, $0.3 \%$ to $0.5 \%$ of all cases of cholelithiasis may lead to gallstone ileus [1,9]. It is a surgical emergency that affects mostly older and female patients $[7,10]$.
The mortality rates vary from $15 \%$ to $18 \%$, with high variation due to age, comorbidities and late diagnoses [4,11]. The former symptoms are vague and intermittent until the bowel obstruction becomes complete. Therefore, variable clinical manifestations can arise, depending on the site of the bowel obstruction. The most common symptoms are abdominal pain and distension, associated to nausea and vomiting [3]. The diagnostic routine begins with simple abdominal radiography, in which Rigler's triad should be looked for. This triad is composed of ectopic gallstones, that move according to the patients' position (seen in $10 \%$ in all cases), pneumobilia and bowel distension $[8,12]$. The contrasted abdominal computed tomography is the best method for diagnosis, as it is possible to identify Rigler's triad in $77 \%$ of all cases, as opposed to $15 \%$ when using simple abdominal radiography $[7,12]$.

The diagnosis of biliary ileum is most often confirmed during surgery $[2,7,8]$, and, in the preoperative period, it occurs between $31 \%$ and $48 \%$ of all cases [2,7].

The treatment is surgical, aiming at the removal of the impacted calculus and the correction of intestinal obstruction and fistula, if possible [1].

This study reports a cholecystoduodenal fistula with jejunal obstruction in a 76-year-old female patient who went through emergency surgical treatment. 


\section{Case Report}

A 76-year-old female patient went to the ambulatorial service of General Surgery in Gaffrée e Guinle Teaching Hospital, located in Rio de Janeiro, Brazil, with reduced clinical condition, irresponsive to verbal stimulation. During medical consultation, her family members reported that the patient was complaining about diffuse colic abdominal pain, associated with anorexia, nausea and postprandial vomits about a month before and failure to pass stool was also reported about 4 days before. There was a weight loss of 20 kilograms and an important decline in the "performance status" during this period. At admission she was asthenic, prostrated, pale $(2+/ 4)$, dehydrated $(4+/ 4+)$, acyanotic, anicteric, afebrile, eupneic, presenting tachycardia and low blood pressure. The abdomen was visibly distended, with slow peristalsis, hypertympanism and diffuses pain during examination. No tumors were found and there were no signs of peritoneal irritation.

The laboratory examinations at the admission showed hemoconcentration, leukocytosis, hyponatremia and deterioration of renal function due to an elevation of nitrogenous compounds. The hypothesis was, then, acute abdomen by obstructive cause, and the patient proceeded for hospitalization. Hydration and hydroelectrolytic replacement were immediately initiated, and a nasogastric tube was introduced for the purpose of decompression of the stomach.

Due to the patient's general state and the information provided by the family, the cause could be a malignant neoplasm, and therefore an upper digestive endoscopic exam was requested. It showed a fistulous orifice measuring approximately $15 \mathrm{~mm}$ in diameter in the duodenal mucosa, located in the transition to its second portion, secreting large amounts of purulent discharge into the duodenal lumen (Figure 1).

A radiographic study of the abdomen revealed the classic Rigler's triad, composed of distended intestinal loops, signs of coin stacking, aerobilia and a suggestive image of ectopic biliary gallstones (Figure 2).

Thereafter, a computed tomography scan confirmed the presence of pneumobilia in intra and extrahepatic ducts and a distended gallbladder by gas. The fistula's path between the gallbladder and the duodenum was identified, as well as important bowel distension, in its duodenal and jejunal portions, with hidro-aeric levels (Figure 3).

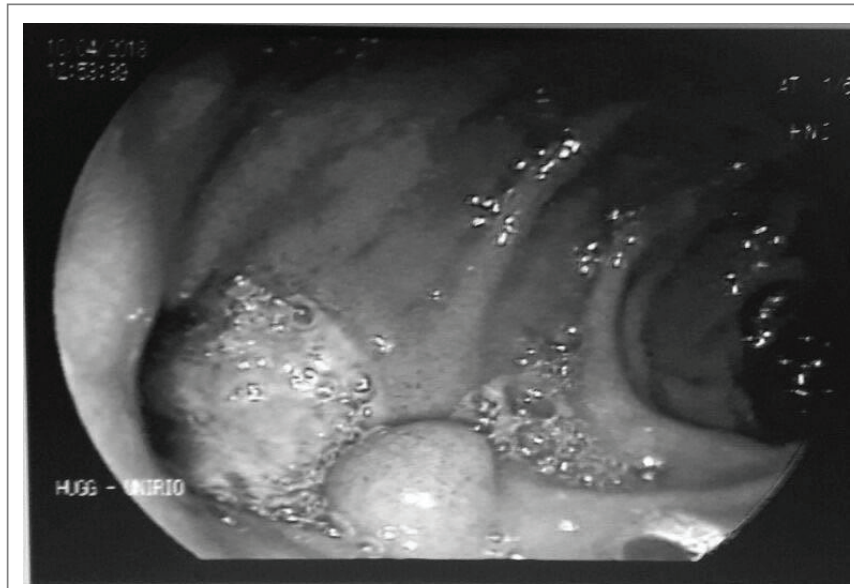

Figure 1: Upper digestive endoscopic exam showing a fistula orifice in duodenum with purulent secretion.
Also in the computed tomography scan, a round intraluminal image with peripheral calcification, measuring approximately $3 \mathrm{~cm}$, was identified in the left flank, which was suggestive of a gallstone (Figure 4).

The patient was referred for surgery, and an exploratory laparotomy was performed. During surgery, a $3 \mathrm{~cm}$ gallstone impacted in a jejunal loop, close to the angle of Treitz, was visualized. There was important upstream loop distension with no ischemic signs (Figure 5).

Enterotomy was also performed, with the removal of the gallstone, and enterorrhaphy, with emptying the content loops in the proximal sense, without manipulation of the gallbladder due to the compromised clinical status of the patient and the intense inflammation (Figure 6).

The postoperative evolution was satisfactory, and there were no complications. The patient took well to the oral diet, receiving

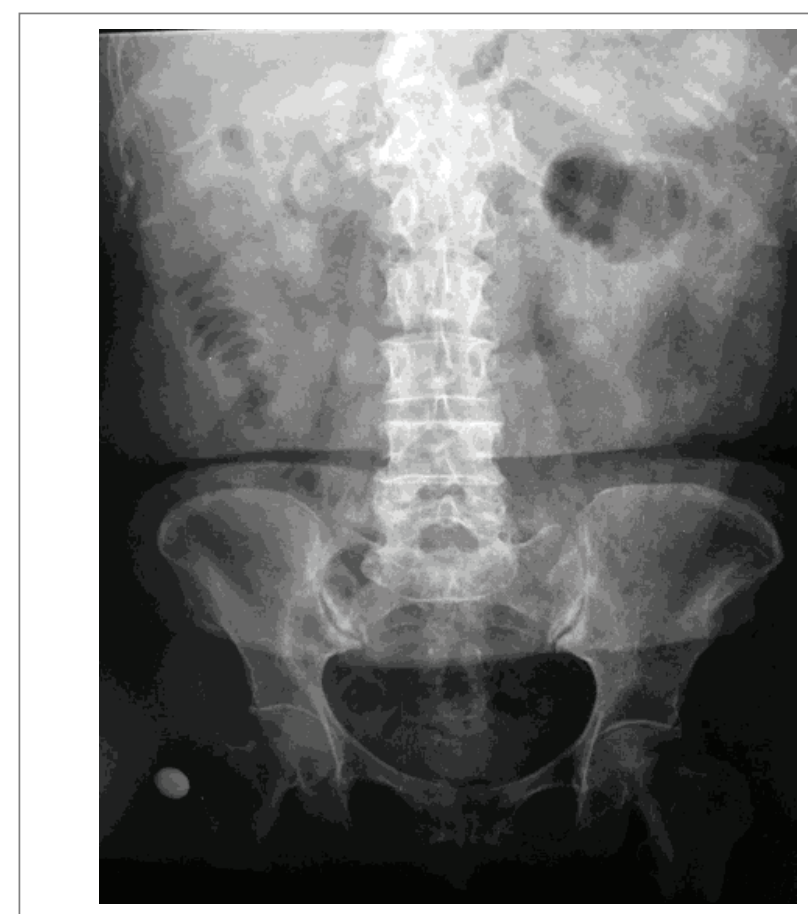

Figure 2: Radiographic study of the abdomen revealing the classic Rigler's triad.

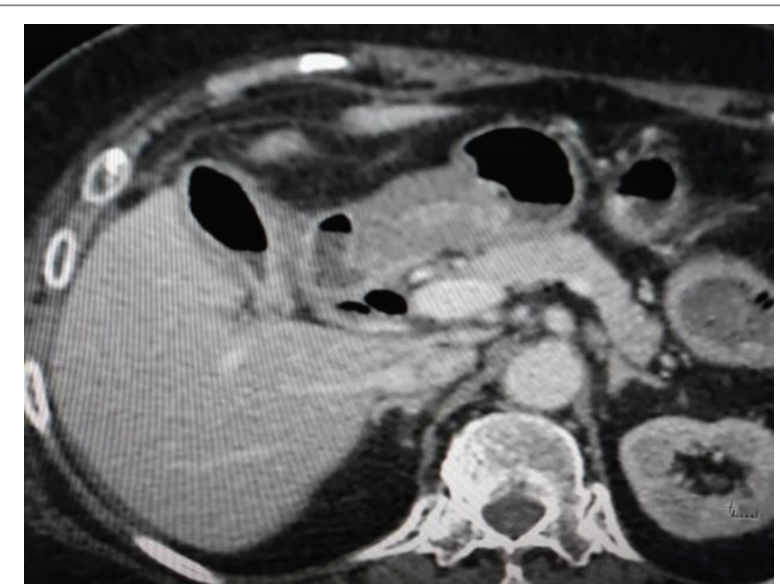

Figure 3: Computed tomography showed aerobilia in intra and extrahepatic ducts and distended gallbladder by gas. 


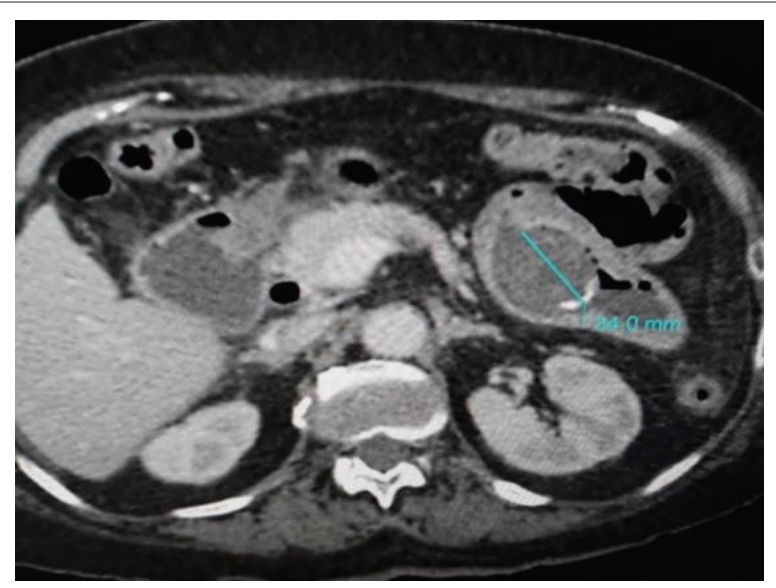

Figure 4: Computed tomography showed a round intraluminal image in the left flank, suggestive of a gallstone.

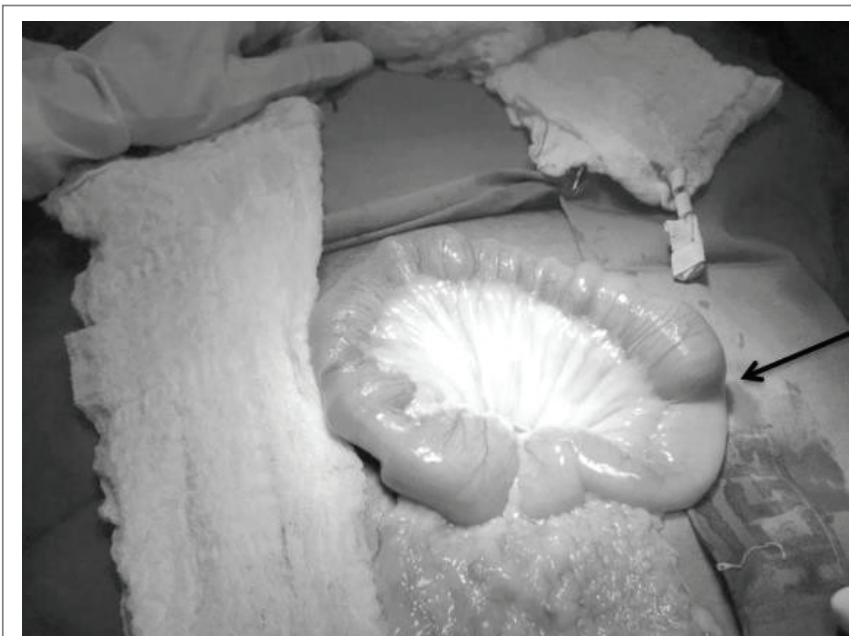

Figure 5: A gallstone impacted in a jejunal loop close to the angle of Treitz.

discharge from the hospital with the recommendation to stay in outpatient follow-up.

\section{Discussion and Conclusion}

Cholelithiasis is one of the most frequent surgical conditions and can lead to potentially dangerous complications as the cholecystoenteric fistula [1,9] and cholecystoduodenal fistula accounts for approximately $75-80 \%$ of all such fistulas [10]. Although rare, this condition must be considered in the differential diagnosis of acute obstructive abdomen.

The morbimortality rates are elevated, as this disease affects mostly older patients with multiple comorbidities, and has frequently late diagnoses $[4,7,11,12]$. This condition is currently responsible for between $1 \%$ and $4 \%$ of all cases of mechanic bowel obstruction $[2,3,7,11,13,14]$.

It is referred to be more common for fistulas to be found in the duodenum due to the proximity of both organs [1,9], although has been reported an incidence of only $3.5 \%$ [13]. They can also be found in the colon, mainly in hepatic angle $(4.1 \%)[1,13]$, jejunum (16\%) [13] and stomach (14.2\%) [13].

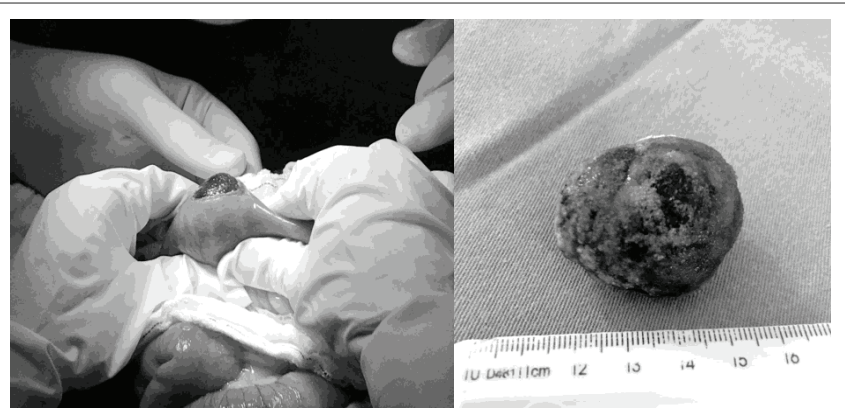

Figure 6: Enterotomy and gallstone removal.

The diagnosis of biliary ileum is rarely done in the preoperative period $[1,2,7]$, being suspected only when, through radiological or imaging exams, the presence of gallstones in the intestinal loop, aerobilia and intestinal obstruction are observed $[1,8,9,14]$.

Generally, the patient reports recent abdominal pain, characterizing acutecholecystitisor cholelithiasis history, with no surgical treatment. In this case, due to the patient's compromised clinical status, and considering the weight loss, intense vomiting and abdominal pain, the hypothesis of malignant neoplasm emerged, and a digestive endoscopy was requested. In this examination, an orifice in the duodenum, secreting purulent discharge, was found, which lead to the diagnosis of cholecystoenteric fistula.

The surgical treatment of the biliary ileum is usually done urgently, and it can be performed in one or two stages, depending on the clinical performance of the patient and the inflammation in the abdominal cavity. The enterolithotomy or enterolithotomy plus cholecystectomy and fistula repair are performed in the initial procedure (one stage), and the enterolithotomy with cholecystectomy only after the patient has recovered (two stages) [13]. The treatment aims to resolve the intestinal obstruction [9] with the removal of the gallstone through enterotomy followed by enterorrhaphy.

Approaching the gallbladder and biliary fistula will depend on the clinical status of the patient and the presence of intense inflammation along the gallbladder [1,9]. In the case presented, the patient had a compromised clinical status, and, during the surgical procedure, a large inflammation involving several intestinal segments was found, and thus we choose not to approach the gallbladder. Therefore, it should be considered the recommendation of elective cholecystectomy for patients with symptomatic cholelithiasis and low surgical risk. The biliary ileum should also be considered as a diagnostic hypothesis when facing a picture of intestinal obstruction in an elderly patient with a previous pathological history of cholelithiasis without prior cholecystectomy [15].

\section{References}

1. Guimarães S, de Moura JC, Pacheco Jr AM, Silva RA (2010) lleo biliar -uma complicação da doença calculosa da vesícula biliar. Rev Bras Geriatr Gerontol 13: 159-163.

2. Doko M, Zovak M, Kopljar M, Glavan E, Ljubicic N, et al. (2003) Comparison of surgical treatments of gallstone ileus: preliminary report. World J Surg 27: 400-404.

3. Brunelli AC, Justino TA, Andrade DA, Mantovani ME (2015) Íleo biliar: relato de caso. Íleo biliar: relato de caso 60: 32-34.

4. Reisner RM, Cohen JR (1994) Gallstone ileus: a review of 1001 reported cases. Am Surg 60: 441-446. 
5. Lassandro F, Gagliardi N, Scuderi M, Pinto A, Gatta G, et al. (2004) Gallstone ileus analysis of radiological findings in 27 patients. Eur J Radiol 50: 23-29.

6. Townsend C, Beauchamp RD, Evers BM, Mattox KL (2014) Sabiston Tratado de Cirurgia: A base biológica da prática cirúrgica moderna. $19^{\text {th }}$ edition, Elsevier, Brasil.

7. de Paula Fraga JB, e Souza TGS, do Nascimento ACR, de Oliveira Moraes E, Vieira FJ (2008) Íleo Biliar-Relato de Caso. HU Revista 34: 141-145.

8. Campelo MRO, Chaves JPG, Menegola VM (2015) Íleo Biliar: um relato de caso. Rev AMRIGS 59: 35-38.

9. Galvão L, Tamez C, Martins T (1978) Fístulas biliares. In: Galvão L (eds) Cirurgia do Aparelho Digestivo. $1^{\text {st }}$ edition, Rio de Janeiro, Guanabara Koogan 567-572.

10. McCreery R, Matthew M (2019) An Unusual Presentation of Cholecystoduodenal Fistula: Abdominal Pain out of Proportion to Exam. Clin Pract Cases Emerg Med 3: 305-306.
11. Browning LE, Taylor JD, Clark SK, Karanjia ND (2007) Jejunal perforation in gallstone ileus-a case series. J Med Case Reports 1: 157.

12. Lobo DN, Jobling JC, Balfour TW (2000) Gallstone ileus: diagnostic pitfalls and therapeutic successes. J Clin Gastroenterol 30: 72-76.

13. Nácul MP, Fabris MV, Da Costa RG (2018) Jejunum-Biliary Intestinal Obstruction-Case Report. Biomed J Sci Tech Res 1: 1063-1065.

14. Aguilar-Espinosa F, Maza-Sánchez R, Vargas-Solís F, GuerreroMartínez GA, Medina-Reyes JL, et al. (2017) Cholecystoduodenal fistula, an infrequent complication of cholelithiasis: Our experience in its surgical management. Rev Gastroenterol Mex 82: 287-295.

15. Sosa GG, Mesa JD, Rodríguez SC, García GAG, Vara SM, et al. (2010) Íleo biliar: complicación poco frecuente de la litiasis vesicular. Rev Cubana Cir. 